\title{
Follicle-stimulating Hormone Induced In Vitro Growth of Small Antral Follicles are not Affected by Gonadotropin-releasing Hormone Agonist or Antagonist Treatment in Mice
}

\author{
(D) Yılmaz Güzel \\ Istanbul Aydın University Faculty of Medicine, Department of Obstetrics and Gynecology, Istanbul, Turkey
}

\section{Abstract}

Objective: In this study, we aimed to investigate if the gonadotropin-releasing hormone (GnRH) agonist and antagonist have any effect on the follicle-stimulating hormone (FSH)-induced-growth of early antral follicles of mice, cultured in vitro, and expressing cognate receptors for FSH and GnRH. For this purpose, small antral follicles were isolated from mouse ovaries and randomly assigned to the groups as control, FSH only, FSH + GnRH agonist, and FSH + GnRH antagonist, and they were cultured for five days.

Methods: The ovaries of C57BL/6 mice $(n=24)$, which were 21 days old, were removed after euthanasia. Small antral follicles measuring $\sim 200 \mu$ in diameter were mechanically isolated after the enzymatic digestion of the ovaries with collagenase and DNase-I. The expression of FSH and GnRH receptors in these follicles was validated by quantitative real time-polymerase chain reaction. Isolated follicles were randomly assigned into four different groups, each consisting of 20-30 follicles: control, FSH only, FSH + GnRH agonist, and FSH + GnRH antagonist.

Results: The FSH treatment significantly enhanced the in vitro growth of the follicles compared to those cultured without FSH after five days of the culture period. The antrum formation was markedly enhanced, and cumulus-oophorus complexes were more easily visible in the FSH-treated follicles compared to control follicles. The mean diameters of follicles treated with the FSH + GnRH agonist or the FSH + GnRH antagonist were not significantly different from those treated with FSH only, but they were significantly greater than control follicles.

Conclusion: These results may suggest that the GnRH agonist and antagonist do not appear to adversely affect the FSH-induced proliferation of mitotic non-luteinizing granulosa cells and the growth of early antral follicles of mice in vitro.

Keywords: Antral follicle, culture, matrigel, follicle-stimulating hormone, gonadotropin-releasing hormone agonist, gonadotropin-releasing hormone antagonist

\section{INTRODUCTION}

Our knowledge about the role of extra-pituitary gonadotropinreleasing hormone $(\mathrm{GnRH})$ and its receptors in ovarian follicle development in humans and other species is very restricted. In the mouse ovary, small antral follicles express the cognate receptors for GnRH and follicle-stimulating hormone (FSH) (13). However, their role in FSH driven growth of these follicles is unknown. Previous studies showed that although systemic administration of $\mathrm{GnRH}$ agonist (GnRHa) was efficient to disrupt estrus cycles, it failed to inhibit follicular development, irrespective of the doses and injection sites (subcutaneous or intramuscular). Around 20\% of healthy growing follicles were still observed during GnRHa treatment, and serum FSH levels were not reduced either by antagonist or agonist treatment, suggesting that GnRHa does not suppress follicular growth even beyond the gonadotropin-dependent stage in mice (4). Also, it might be challenging to interpret the intra-ovarian actions of GnRH analogs when they are administered systemically due to its effect on the hypothalamic-pituitary-ovarian axis. One in vitro study showed that GnRHa exerts diverse actions on granulosa cells over the course of follicular growth. One down-regulates granulosa cell proliferation in immature follicles as well as steroidogenesis in mature follicles, and the other upregulates apoptosis of granulosa cells regardless of the stages of follicular growth (5). It is unclear whether in vitro GnRH analog treatment has any impact on FSH induced growth in in vitro conditions of 
small antral follicles isolated from mice and expressing FSH and $\mathrm{GnRH}$ receptors. We aimed to address if GnRHa and antagonist has any effects on FSH induced in vitro growth mouse early antral follicles expressing cognate receptors for FSH and GnRH.

\section{METHODS}

\section{Study Design}

We designed this study to investigate in vitro conditions if GnRHa and antagonist treatment have any impact on FSH induced growth of isolated mouse early antral follicles expressing cognate receptors for FSH and GnRH. For this purpose, small antral follicles were isolated from mouse ovaries and randomly assigned to the groups as control, FSH only, FSH + GnRHa, and $\mathrm{FSH}+\mathrm{GnRH}$ antagonist and cultured for five days.

\section{Follicle Isolations from Mice}

All experiments were conducted 21-day-old C57BL/6 mice. The Institutional Animal Care and Use Committee of İstanbul Aydın University Faculty of Medicine approved the protocol (issue number: 2015-20). Animals were euthanized by cervical dislocation, and ovaries were removed, minced into two or three fragments in pre-warmed Dulbecco modified eagle medium-F12 (DMEM-F12) culture medium. Then the pieces were disassociated with collagenase, DNase-I in DMEM-F12 supplemented with 5\% bovine serum albumin (BSA) for 30 minutes at $37^{\circ} \mathrm{C}$. Small antral follicles were mechanically isolated under a stereomicroscope (Olympus SZX12, Olympus America Inc., Center Valley, PA, USA) and randomly assigned to the groups to be cultured for five days.

\section{Culture Medium Formulation}

Isolated follicles were cultured in (HEPES)-buffered DMEM-F12 culture medium with $10 \%$ fetal bovine serum supplemented with and without $100 \mathrm{mIU} / \mathrm{mL}$ recombinant FSH, $3 \mathrm{mg} / \mathrm{mL}$ BSA, and $1 \%(v / v)$ Penicillin-G, streptomycin, amphotericin-B cocktail at $37{ }^{\circ} \mathrm{C}$ and $5 \% \mathrm{CO}_{2}$ in air. GnRHa leuprolide acetate (50 ng/ $\mathrm{mL}$ ) and antagonist cetrorelix acetate $(5 \mathrm{ng} / \mathrm{mL}$ ) were used at the concentrations that were previously shown to have in vitro activity on granulosa cells and ovarian tissue samples (6).

\section{D Culture on Matrigel}

Growth factor reduced matrigel was used in the study, we described previously (7). In brief, matrigel was thawed at $4{ }^{\circ} \mathrm{C}$ slowly, and then diluted with DMEM-F12 medium in a 1:1 ratio and added as $100 \mathrm{uL}$ volume in each well of the 96 well culture plate and kept at $4{ }^{\circ} \mathrm{C}$. Then isolated follicles were placed in one follicle for each well fashion and placed in the incubator. Once the matrigel is solidified 30 minutes after incubation, $100 \mathrm{uL}$ of complete media was added on top of it and replenished every day. The images of the follicle diameter were taken every day using an Olympus IX71 microscope, and follicle diameter was measured using specialized software (Olympus DPS, USA).

\section{Gene Expression Analysis by Quantitative Real Time- Polymerase Chain Reaction}

RNA isolation from isolated follicles was performed by Quick-RNA $^{\mathrm{TM}}$ MicroPrep (Zymo Research) following the manufacturer's guidelines. RNA quantification was completed by spectrophotometric read at $260 \mathrm{~nm}$ by Nanodrop (Thermo Scientific). 1000 ng cDNA synthesis was performed by reverse transcription of RNA using moloney murine leukemia virus reverse transcriptase (Invitrogen). Light Cycler ${ }^{\circledR} 480$ SYBR Green I Master (Roche) was used to quantify relative mRNA expression levels of GnRH-R and FSH-R genes.

$\begin{array}{lll}\begin{array}{ll}\text { Primers Used } \\ \text { Gene }\end{array} & \\ \text { Sequence } & \\ \text { GnRH- } & R & \text { F5'-GGCTGCCTCtTCATCCCCCT-3' } \\ & R & \text { 5'-CGTTCTCAGCCGAGCTCTTGGG-3' } \\ \text { FSH-R } & \text { F } & \text { 5'-ACACAACTGTGCATTCAACGG-3' } \\ & R & \text { 5'-GACTTGTTGCAAATTGGATGA-3' } \\ \text { GAPDH } & \text { F } & \text { 5'-ACAGTCAAGGCCGATAATGG-3' } \\ & R & \text { 5'-TCTCCATGGTGGTGAAGACA-3' }\end{array}$

\section{Statistical Analysis}

Follicle diameter is continuous data and stated as the mean \pm standard deviation. The comparison of the groups was made using ANOVA and multiple comparison Tukey post hoc tests.

\section{RESULTS}

We first conducted a validation experiment to assess if the experimental design is appropriate to test the effects of $\mathrm{GnRHa}$ and antagonist on in vitro growth of early antral follicles in mice. For this purpose, small follicles that were $200-300 \mu$ in diameter and had antrum formation were selected for the study. The expression of GnRH and FSH receptor in these follicles were verified with quantitative real time-polymerase chain reaction (Figure 1). Then, isolated follicles were randomly assigned into four groups: no FSH (control), FSH only, FSH + GnRHa, and FSH $+\mathrm{GnRH}$ antagonist, each group consisting of 23-25 follicles. The results shown below are the mean values of three independent replicates of the experiments. The initial diameter of the follicles 


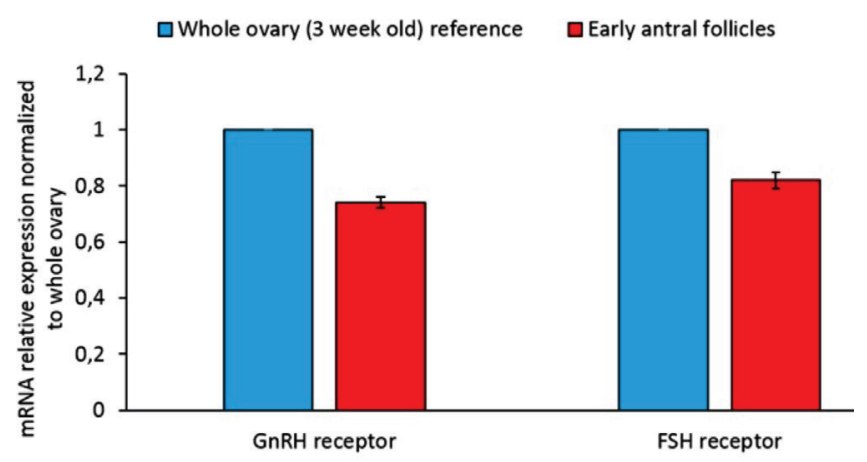

Figure 1. mRNA relative expression normalized to whole ovary FSH: Follicle-stimulating hormone, GnRH: Gonadotropin-releasing hormone at the beginning of the experiment was comparable among the groups (Figure 2). At the end of the culture period, the mean follicle size $(\mu)$ of the follicles treated with FSH was notably higher than their counterparts incubated without FSH $(657 \pm 62$ vs. $325 \pm 30$ respectively, $p<0.01)$. Follicles treated with $\mathrm{FSH}+$ GnRHa (545 \pm 61 vs. $657 \pm 62$ respectively, $p>0.05$ ) or with FSH + GnRH antagonist ( $615 \pm 46$ vs. $657 \pm 62$ respectively, $p>0.05)$ were not different from those treated with FSH only (Figure 2) in the mean of diameter. When the percentage of growth was compared among the groups it appeared that control follicles treated without FSH achieved a growth rate of $61 \%$ at the end of 5 day culture period, which was significantly lower compared those treated with FSH $(204 \%, p<0.01)$, FSH + GnRHa $(162 \%$, $p<0.01)$ and FSH + GnRHa $(186 \%, p<0.01)$ groups. We observed no considerable differences between FSH, FSH + GnRHa, and $\mathrm{FSH}+\mathrm{GnRH}$ antagonist groups in terms of follicular growth rate.

\section{DISCUSSION}

We performed this study to investigate in vitro conditions if GnRHa and antagonist treatment have any impact on FSH induced growth of isolated mouse early antral follicles expressing cognate receptors for FSH and GnRH.

Our results suggest that in mice, FSH-driven in vitro growth of small antral follicles is not adversely affected by GnRHa or antagonist co-treatment in vitro. It has been shown by different groups that mouse ovaries express the GnRH receptor (1-4). In rats, the comparison of GnRH receptor expression at different follicular stages demonstrated that these mRNA levels of the $G n R H-R$ gene vary depending on follicles degree of maturation as well as the estrous cycle stage. While follicles in preantral and small antral stages and corpora lutea showed lower expression, Graafian and atretic follicles had the highest level of GnRH-R gene expression $(3,8,9)$. In human ovary, $\mathrm{GnRH}$ receptors are localized in granulosa cells from the antral stage and in the
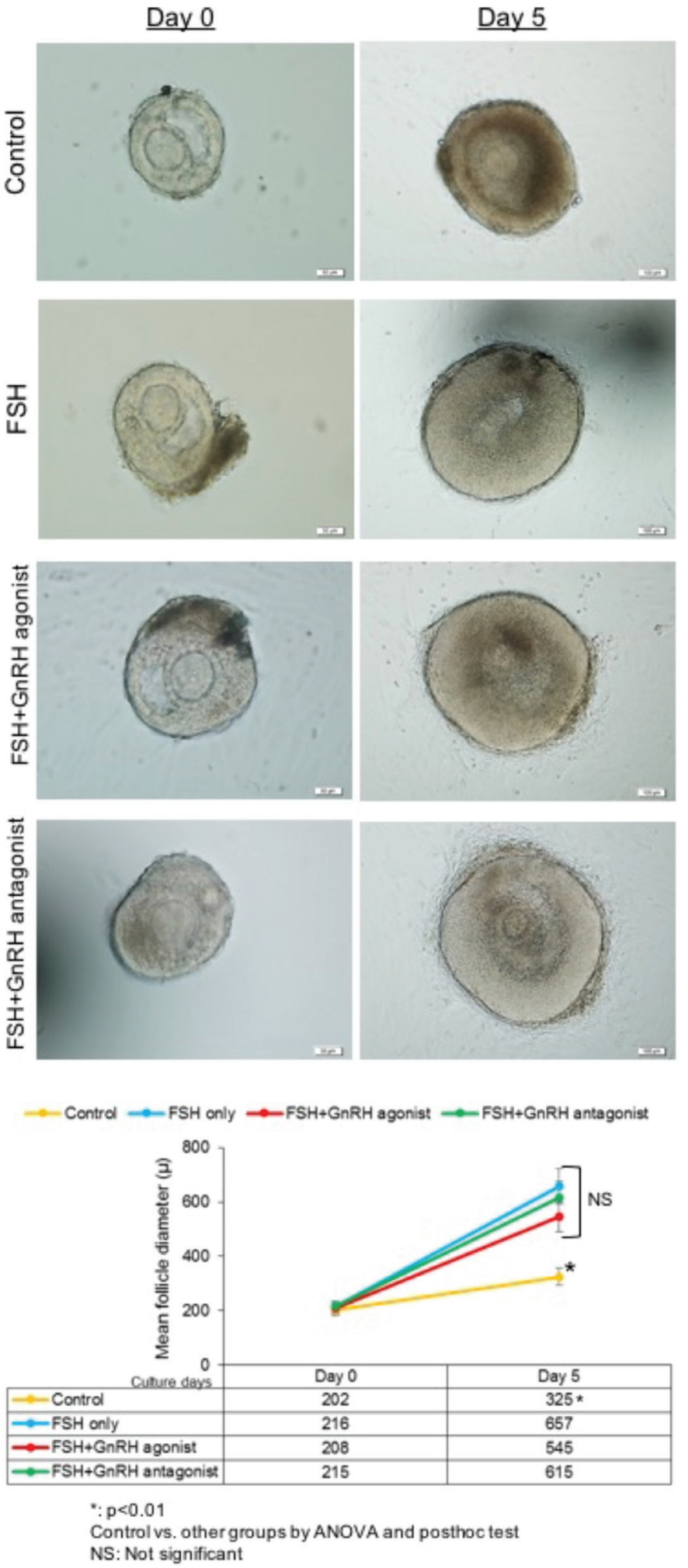

Figure 2. Control vs. other groups by ANOVA and posthoc test NS: Not significant, FSH: Follicle-stimulating hormone, GnRH: Gonadotropin-releasing hormone

corpus luteum (10). Exploring intra-ovarian actions of GnRH analogs is hampered by the fact that the systemic administration of GnRH analogs affects the hypothalamic-pituitary-ovarian axis, 
precluding one from investigating the sole intra-ovarian action of GnRH analogs on folliculogenesis. We, therefore, aimed to investigate the effect of GnRH analogs, namely, GnRHa leuprolide acetate and antagonist cetrorelix acetate on FSH driven in vitro growth of small antral follicles in an isolated culture that express FSH and GnRH receptors.

Although not conducted in human antral follicles, our data might be particularly important from the perspective of assisted reproduction in humans because controlled ovarian stimulation is carried out with FSH treatment together either with a GnRHa or antagonist. It is unknown whether GnRH analogs have any effect on the growth kinetics of small antral follicles that have not reached 2-10 $\mathrm{mm}$ diameter, therefore, are not visible on ultrasound.

Our study has several limitations as follows: First, this is an in vitro study on the individual culture of isolated small antral follicles. Therefore, the paracrine/autocrine interaction of locally produced growth factors in the intra-ovarian environment that may potentially affect or modify the actions of GnRH analogs cannot be assessed using this model. Second, matrigel contains some growth factors such as EGF, FGF, and TGF, in addition to its main components, extracellular matrix proteins collagen, laminin, and entactin, etc. They may change the response of the follicles to FSH with and without GnRH analogs. Third, the competence of these in vitro grown follicles for full growth, ovulation, mature oocyte yield, fertilization rate, and embryo development could not be assessed using this experimental methodology. Forth, GnRHa and antagonists were not tested at different concentrations. After a certain threshold level, they may have a different action after they bind to their cognate receptors in the follicle.

\section{Ethics}

Ethics Committee Approval: The Institutional Animal Care and Use Committee of İstanbul Aydın University Faculty of Medicine approved the protocol (issue number: 2015-20).
Informed Consent: Not applicable.

Peer-review: External and internal peer-reviewed.

Financial Disclosure: The author declared that this study received no financial support.

\section{REFERENCES}

1. Torrealday S, Lalioti MD, Guzeloglu-Kayisli O, Seli E. Characterization of the gonadotropin releasing hormone receptor (GnRHR) expression and activity in the female mouse ovary. Endocrinology 2013;154:3877-87.

2. Mo Y, Peng P, Zhou R, He Z, Huang L, Yang D. Regulation of gonadotropinreleasing hormone $(\mathrm{GnRH})$ receptor-I expression in the pituitary and ovary by a GnRH agonist and antagonist. Reprod Sci 2010;17:68-77.

3. Horicks F, Van Den Steen G, Gervy C, Clarke HJ, Demeestere I. Both in vivo FSH depletion and follicular exposure to Gonadotrophin-releasing hormone analogues in vitro are not effective to prevent follicular depletion during chemotherapy in mice. Mol Hum Reprod 2018;24:221-32.

4. Horicks F, Van Den Steen G, Houben S, Englert $\mathrm{Y}$, Demeestere I. Folliculogenesis Is Not Fully Inhibited during GnRH Analogues Treatment in Mice Challenging Their Efficiency to Preserve the Ovarian Reserve during Chemotherapy in This Model. PLoS One 2015;10:e0137164.

5. Huang J, Wang X, Li Z, Ma R, Xiao W. Effects of GnRH agonists on the expression of developmental follicular anti-mullerian hormone in varying follicular stages in cyclic mice in vivo. Mol Med Rep 2015;12:4305-13.

6. Bildik G, Akin N, Senbabaoglu F, Sahin GN, Karahuseyinoglu S, Ince U, et al. GnRH agonist leuprolide acetate does not confer any protection against ovarian damage induced by chemotherapy and radiation in vitro. Hum Reprod 2015;30:2912-25.

7. Oktem $\mathrm{O}$, Buyuk E, Oktay K. Preantral follicle growth is regulated by c-Jun-Nterminal kinase (JNK) pathway. Reprod Sci 2011;18:269-76.

8. Bauer-Dantoin AC, Jameson JL. Gonadotropin-releasing hormone receptor messenger ribonucleic acid expression in the ovary during the rat estrous cycle. Endocrinology 1995;136:4432-8.

9. Whitelaw PF, Eidne KA, Sellar R, Smyth CD, Hillier SG. Gonadotropin-releasing hormone receptor messenger ribonucleic acid expression in rat ovary. Endocrinology 1995;136:172-9.

10. Maggi R, Cariboni AM, Marelli MM, Moretti RM, Andre V, Marzagalli M, et al. GnRH and GnRH receptors in the pathophysiology of the human female reproductive system. Hum Reprod Update 2016;22:358-81. 